\title{
ÁRBOLES Y ARBUSTOS EN MITOS GUARANÍES SOBRE EL ORIGEN Y EL FIN DEL MUNDO: ELUCIDACIÓN DE ALGUNAS EXPRESIONES FITONÍMICAS
}

\author{
HÉCTOR A. KELLER ${ }^{1}$
}

\begin{abstract}
Summary: Keller, H. A. 2013. Trees and shrubs in guarani myths about the origin and the end of the world: elucidation of some plant names. Bonplandia 22(2): 149-158.

The role of some trees and shrubs in cosmogony and judgment day myths of southern Guarani people is studied by means of some narratives recorded in indigenous communities of Misiones Province, Argentina. With the purpose of obtaining a clarification of the etymology of some plants names more frequent in guarani language, these narratives are complemented with phytosociologic observations and bibliographic references.
\end{abstract}

Key words: Guarani plant names, yvyra, tree, ka'a, forest.

Resumen: Keller, H. A. 2013. Árboles y arbustos en mitos guaraníes sobre el origen y el fin del mundo: elucidación de algunas expresiones fitonímicas. Bonplandia 22(2): 149-158.

Se investiga el rol de algunas especies arbóreas en la cosmogonía y los mitos sobre el fin del mundo de los guaraníes meridionales a partir de narrativas recogidas en comunidades indígenas de la provincia de Misiones, Argentina. Con el fin de dilucidar la etimología de algunos de los fitónimos más corrientes del idioma guaraní, estas narrativas son complementadas con observaciones fitosociológicas e información bibliográfica.

Palabras clave: Fitónimos guaraníes, yvyra, árbol, ka’a, selva.

\section{Introducción}

Las investigaciones en el campo de las taxonomías folk y la etnotaxonomía se sustentan en el análisis de los nombres indígenas de especies individuales o de grupos de organismos vivos. Como lo evidencian innumerables contribuciones específicas que se ocupan de la etnotaxonomía y fitonimia indígena, el estudio etimológico de los fitónimos constituye un requisito previoineludible para abordarpatrones nomenclaturales o sistemas de clasificación de las plantas (cfr. Berlin, 1973; Cadogan, 1957; Martínez, 2009, Scarpa, 2007; Suarez, 2010, 2011). En su obra sobre fitónimos primitivos,
Lange (1966) sugiere que los nombres más antiguos de las plantas son expresiones muy simples que generalmente aluden a caracteres morfológicos notables, a algún uso destacado, o bien a aspectos relacionados a la mitología. En el primer caso, además de un conocimiento específico de la lengua es pertinente que el investigador examine o tenga en cuenta la morfología de las especies nombradas. Por ejemplo, el fitónimo guaraní pindo (upi: subir; ndo: hoja) transmite la noción de "follaje apiñado en el extremo de un eje vertical", es decir que se trata de una expresión que sugiere la representación de una palmera, y podría decirse que la especie así llamada es "la palmera

\footnotetext{
${ }^{1}$ Investigador del CONICET, Facultad de Ciencias Forestales, UNaM, Instituto de Botánica del Nordeste, (CONICETUNNE, Facultad de Ciencias Agrarias), C.C. 209, 3400 Corrientes, Argentina. kellerhector@hotmail.com
} 
por antonomasia" para el grupo cultural que la nombra de ese modo. En el segundo caso, el investigador debe estar al tanto de los usos principales que la planta nombrada tiene o ha tenido en el pasado. Podemos mencionar a modo de ejemplo la expresión yvy (textil) empleada por los guaraníes para denominar a una especie arbórea cuya corteza constituye una fuente de fibras textiles (Cadogan, 1992; Keller, 2009). Es más complejo el escrutinio etimológico cuando el nombre de una planta se halla relacionado a la mitología. En ese caso, la traducción literal de una expresión nominal y los conocimientos acabados sobre la morfología y los usos de la planta nombrada, pueden constituirse en elementos de suma utilidad, pero no conforman suficiente materia prima para lograr una aproximación al sentido esencial que atesora el fitónimo en el contexto de la cultura que lo ha acuñado. Es usual que este tipo de fitónimos constituyan elementos propiciadores o disparadores para el estudio de diferentes aspectos de la mitología cosmogónica (González, 2009; Keller, 2003, 2011). Recíprocamente el estudio de los mitos cosmogónicos puede aportar elementos de juicio para abordar el significado de algunos fitónimos (Keller, 2013). Atendiendo a una ampliación de esta última posibilidad de indagación fitonímica, la presente contribución constituye un intento de abordar algunas expresiones de la nomenclatura botánica de los guaraníes a partir del estudio del rol de ciertos árboles en los mitos cosmogónicos y apocalípticos. Entre estas expresiones se encuentra la palabra yvyra, ampliamente empleada en la región guaranítica para significar "árbol", "especie leñosa" o simplemente "leño".

\section{Material y Métodos}

Las diversas interrelaciones que tienen lugar entre el hombre y su medio ambiente vegetal constituyen el objeto de estudio de la Etnobotánica (Albuquerque \& Hurrell, 2007). Los resultados que se presentan aquí son subalternos a un estudio etnobotánico iniciado en diversas aldeas guaraníes de la provincia de Misiones en el año 1998 y que se extiende hasta la actualidad. Para estructurar el argumento desarrollado a partir de estos resultados, se ha amalgamado la información etnobotánica de campo con estudios sobre los atributos morfológicos, utilitarios y fitosociológicos de las especies que se trabajan; sin embargo la discusión sustancial que se propone se circunscribe en la Mitografía, definida por la Real Academia Española (1973) como la ciencia que trata el origen y la explicación de los mitos. Contribuciones mitográficas previas sugieren que diversos atributos de las especies, poblaciones o elementos resultantes de un proceso creativo o transformativo, pueden aportar argumentos valiosos para el estudio del origen de los mitos guaraníes (Keller, 2003, 2011, 2013).

Material examinado: CALOPHYLLACEAE. Calophyllum brasiliensis Cambess. ARGENTINA. Misiones. San Ignacio, $27^{\circ} 16^{\prime} 34,4^{\prime \prime}$ S - 55 34'11,9" W, 19-X-2008, Keller 6430 (CTES). MELIACEAE. Cedrela fissilis Vell. Misiones. Eldorado, Ruta prov. 17, paraje Pozo Azul, Aldea guaraní Tekoa Arandu, 10-X-2003, Keller 2505 (CTES). BIGNONIACEAE. Handroanthus heptaphyllus (Vell.) Mattos. Misiones. Dep. Guaraní. Predio

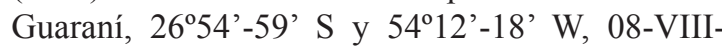
2002, Keller \& Robledo 2210 (CTES). FABACEAE. Holocalyx balansae Micheli. Misiones. Lib. Gral. San Martín, Municipio El Alcázar, 23-IX-2000, Keller 318 (CTES). AQUIFOLIACEAE. Ilex dumosa Reissek var. guaranina Loes. Corrientes. Ituzaingó. Puerto Valle, $27^{\circ} 38^{\prime} 32,5^{\prime \prime} \mathrm{S}-56^{\circ} 30^{\prime}$ 34,4" W, 31-VIII-2013, Keller \& al. 11525 (CTES); Ilex paraguariensis A. St.-Hil. Misiones. Guaraní, Aldea aborigen Taruma Poty, arroyo El Soberbio, 18I-2006, Keller \& al. 3400 (CTES). LAURACEAE. Nectandra megapotamica (Spreng.) Mez. Misiones. Eldorado, Parque Schwelm, 14-X-2010, Keller \& Dummel 9270 (CTES). SOLANACEAE. Solanum americanum Mill. Misiones. Eldorado, A $1 \mathrm{~km}$ al sur del puerto de Eldorado, 20-VII-2003, Keller 2213 (CTES). CELTIDACEAE. Trema micrantha (L.) Blume. Misiones. San Ignacio, base norte del peñón Osununú, 10-II-2011, Keller 9616 (CTES).

\section{Los guaranies meridionales}

En la actualidad los guaraníes meridionales conforman una población de más de 98.000 individuos (Azevedo \& al., 2009), constituyéndose en una de las mayores 
poblaciones indígenas de las tierras bajas de América del Sur (Assis \& Garlet, 2004). Son tres los grupos o parcialidades que conforman la nación guaraní oriental, los Ava Chiripa, los Mbya y los Pa'i Tavytera. En el Paraguay los guaraníes Ava Chiripa se concentran en los departamentos Canindeyú y Alto Paraná, ocupando una posición intermedia entre los Mbya que son más australes y los Pa'i tavytera que se ubican al norte de la Región Oriental. En el Brasil ocurre una distribución similar, mientras los Ava Chiripa y los Pa'i Tavytera cuentan con numerosas comunidades en los estados de Mato Grosso do Sul y Paraná, los Mbya alcanzan a extenderse más al sur y hacia el oriente, incluyendo también los estados de Santa Catarina y Río Grande do Sul. En Argentina la población guaraní apenas supera los 6.500 individuos, de los cuales alrededor de 1.000 pertenecen a la parcialidad Ava Chiripa y los restantes a la parcialidad Mbya. (Azevedo \& al., 2009); ambos grupos distribuidos en la provincia de Misiones.

Los registros más antiguos de la presencia guaraní en Misiones, Argentina datan de unos 1.200 años A.P. (Poujade, 1995), pero su arribo a lo que hoy se conoce como Bosque Atlántico del Alto Paraná se remonta a más de 2000 años, tratándose ya en ese entonces de un pueblo agricultor de roza y quema (Noelli, 2006; Schmitz, 1991). En Misiones, Argentina, el avance de la frontera agropecuaria moderna ha desplazado a la mayoría de las comunidades guaraníes actuales desde las fértiles planicies que se extienden a lo largo de los ríos Paraná y Uruguay hasta las pedregosas estribaciones de la serranía central de la provincia. La ausencia de territorios propicios para desarrollar actividades acordes a los preceptos de su cosmología se refleja en advertencias y malos presagios que declaran en sus discursos los dirigentes espirituales guaraníes. Como se ejemplifica en este trabajo, tales malos presagios han sido elaborados con categorías conceptuales propias de sus mitos cosmogónicos.

\section{Resultados y Discusión}

Los árboles y el origen primario de la tierra

Para abordar la génesis guaraní en primer lugar es necesario dedicar algunos párrafos a la máxima figura del panteón de los guaraníes meridionales. Entre los $A v a$ Chiripa la denominación corriente del ser supremo es Kuara'y Ru Ete, "el genuino padre del sol"', una expresión que también es traducible de manera más disgregada como "el genuino padre del hijo de la percepción"3, tratándose esta última acepción de una fórmula redundante que alude a una personificación de la conciencia o del conocimiento de las cosas (kuaa). Este sujeto supremo, denominado Namandu por los Mbya, es el progenitor del sol y responsable de la luz solar. Estimado por los guaraníes como su primer ancestro aún vivo, es su arquetipo cultural, es decir aquel quien más sabiduría acumulada y participación en la cultura posee. Habiéndose creado a sí mismo en los inicios del tiempo ${ }^{4}$, y hallándose entonces sólo, carente de todo contexto cultural del cual aprehender cualquier cosa, tuvo que crear el mundo, el cual es entendido como una expresión de su subjetividad suprema. Dicha labor creativa se extiende cotidianamente hasta la actualidad, pues se considera que la luz solar es su contemplación creativa vigente.

Algunos mitos cosmogónicos guaraníes señalan que la creación de la llamada "primera tierra" fue efectuada mediante una labor de cestería. Los cestos tradicionales guaraníes se manufacturan usando dos varas cruzadas que constituyen la estructura de su base. Nande ru ojapo 'ima yvy rai'î raka'e ogueru mokõi yvyra' $i$ oñono'imavy. Yvy oñepyrũ'i jave a'e va'epy peicha kyrĩ'i ajakarãmi rive'i omoñepyrũ. "Nuestro padre cuando estaba por hacer la tierra trajo dos palos de yvyratái y los acostó (Vera Tataendy). La tierra primigenia se comenzó a hacer simplemente de la manera cómo se inicia la elaboración de un canasto" (Vera Endy).

La madera denominada yvyratái, que se menciona como material constituyente de estas varas creativas, es el duramen del árbol llamado

${ }^{2}$ Kuara'y: sol; ru ete: padre genuino

${ }^{3}$ Kuaa: sabiduría, percepción, contemplación; ra'y: hijo; ru: padre; ete: genuino.

${ }^{4}$ Nande Ru Papa Tenonde gueterã ombojera pytũ ymagui: "Nuestro Padre Último-último Primero, su propio cuerpo creó de las tinieblas primigenias (Cadogan, 1959). 
yvyrapepe, el leño más denso y duro asequible en la provincia de Misiones. Dicho material ha sido además utilizado para la obtención de fuego, conformando una de las piezas que componen los encendedores tradicionales guaraníes (Keller inéd.). La expresión yvyratái, denota dos posibles traducciones, "madera dura" y "madera del fuego", ambas tan ligadas a sus propiedades que probablemente sean etimologías conniventes, es decir que es posible que a partir de la cualidad combustible de este material tan elemental e inaugural la expresión "ata" (duro) se haya establecido como consecuencia de la dureza de la "madera del fuego"; o bien al contrario, que la expresión "ata" (fuego) sea una consecuencia de la facultad de ignición adjudicada a la "madera dura".

La complementariedad entre las propiedades estructurales creativas y el poder de ignición de este material primigenio, se debe a que la combustión rápida es considerada por los guaraníes como una reproducción de la conciencia de su arquetipo cultural, o lo que es equivalente, delaenergíaluminosaincandescente del primer ancestro, energía que es almacenada en algunas especies maderables. Además del yvyratái cabe mencionar a diversas lauráceas denominadas aju'y (ju: ígneo, luminoso, áureo, y el sufijo $y$ es una contracción de yvyra: madera), es decir "madera luminosa". En coincidencia con la etimología de esta expresión genérica, algunos de los árboles cuyos nombres llevan este vocablo, son también utilizados como base de los encendedores tipo taladro (Keller, 2008). Complementariamente, una especie denominada aju'y mirĩ (madera ígnea primigenia) es mencionada como sostén de la tierra en una variante del mito de la creación (Cadogan, 1992).

La concepción, ya sea de un ser humano o de la vida en general, es entendida por los guaraníes como un acto de ignición, ya que implica reproducir en la tierra un fragmento de la conciencia o energía luminosa del primer ancestro. Es por esa razón que en un mundo demasiado atiborrado de eventos e intencionalidades deletéreas, la ausencia de espacios propicios para la procreación y el establecimiento de una nueva comunidad, es anunciada por los sacerdotes guaraníes en términos de la ausencia de espacios propicios para encender una fogata (iNdaipa'ũvéi tata rupa!: ¡No quedan más sitios donde encender un fuego!), entendida la fogata como la disposición de bases leñosas necesarias para dar continuidad a la replicación de la labor creativa cotidiana del primer ancestro. Como procrear y cultivar son categorías indistinguibles dentro de ciertos esquemas de sociabilidad guaraní, este presagio ignífugo alude también a la escasez de superficies selváticas edafológicamente adecuadas para incinerar la vegetación rozada $\mathrm{y}$, a expensas de ello, cultivar las plantas anuales necesarias para la subsistencia y la procreación.

Ciertas narrativas guaraníes aseguran que el cedro misionero o yvyra ñamandu, "el árbol del creador", aunque no se usa para encender fuego también contiene en su interior una porción importante de la energía creativa del sujeto supremo. De acuerdo con Litaiff (1999), sus ejemplares representan al dios solar marcando el sitio donde las almas de los niños descienden para encarnarse durante el ritual del bautismo. Asimismo, a la espera de que la sabiduría creativa del primer ancestro se libere en el contexto de ocasiones litúrgicas, se emplean sus troncos como postes en la construcción del templo (opy) y como madera para su mobiliario (Keller, 2010). Con la resina de esta y otras especies, se confeccionaban los antiguos labretes (tembeta) o adornos labiales, los cuales pendiendo desde la parte superior del mentón de los hombres adultos, constituían un símbolo de masculinidad típico de algunos grupos guaraníes (Müller, 1935). En su forma aguzada y su color ambarino se buscaba representar los rayos solares, es decir, la energía creativa del primer ancestro, encarnada en aquellos hombres que dan continuidad a su linaje energético.

\section{Árboles y orígenes secundarios de la tierra}

Los guaraníes constituyen un grupo étnico destacado por sus constantes admoniciones apocalípticas (Nimuendaju, 1914). De hecho, en la actualidad algunos dirigentes religiosos guaraníes se encuentran aguardando un evento apocalíptico, calificado como el advenimiento de las tinieblas eternas ( $p y t u \tilde{u}$ ete), el cual es explicado como el resultado esperable de un interés decreciente por parte del creador para con su progenie terrenal corrompida. Tal 
desinterés desencadenaría el fin de la vida en la tierra ya que la privaría de su mirada luminosa y creativa. Namandu oikechetama opy guachu a'e oguereko va'epy, oikeramo oke ombotymaramo, ndoguéi mara, ndoecha peve'i mara yvypy jaiko'i va'e, pytũma ojapo va'erã, a'epy ñande ũndipa'i aguãpy ma: "El (progenitor del) Sol tiene ya intenciones de entrar a su gran templo, cerrando la puerta para no volver a salir, (es decir) pretende no volver a contemplar la tierra en la que estamos, sumirla en las tinieblas, y de ese modo acabar con nosotros". Como la estructura leñosa que fundamenta el mundo es una suerte de metáfora que alude a la franja determinada por el desplazamiento que en un ciclo anual el sol efectúa en el firmamento, tal estructura constituye un dispositivo que nutre constantemente a la tierra con la conciencia lumínica del sol. De manera que la admonición sobre el advenimiento de las tinieblas es equivalente a la también vaticinada remoción de dicha estructura: "las varas de madera cruzadas hasta hoy permanecen como soporte de la tierra, en cuanto el Ser Creador las retire el mundo se desplomará" (Nimuendaju, 1914: 155). En virtud de ello los sacerdotes guaraníes sugieren que una de las pocas chances de sobrevivir es disponer de su contemplación diferida acumulada en las maderas; pero para que ello sea efectivo es necesario preservar el fuego enviado por el creador desde las alturas mediante los rayos o descargas eléctricas. A'e va'e pytũ oikoramo ndoguei mo'áipy a'e va'e tata: "Cuando se ciernan las tinieblas ese fuego es el (único) que no habrá de extinguirse". Aseguran además que los rayos interceptan y ultiman con más frecuencia al árbol llamado tajy en virtud de que se halla custodiado por una esencia maligna. Las raíces de este fitónimo (ata: fuego y jy: descenso) enuncian su atributo de ser el medio por el cual "los rayos justicieros descienden". De acuerdo con Cadogan (1957: 42) para los Mbya se trata de un árbol de alma indócil, por lo cual fragmentos de madera de un ejemplar herido por un rayo se utilizan como amuletos.
Pero las narrativas sobre cataclismos también son abundantes en relación a tiempos pretéritos. Mitos guaraníes relatan que la tierra fue ya devastada en el pasado por dos cataclismos de naturaleza muy diferente a aquel que se vaticina para el futuro; un colosal incendio (tata guachu) y una catastrófica inundación (yy guachu).

Cadogan (1968: 85), refiere un mito mbya guaraní sobre la sucesión secundaria posterior al gran incendio. Después de ese evento sólo existía un espécimen de ka'a ete'i (la hierba genuina), se trata de una de las primeras especies herbáceas que suele germinar después de la roza y quema de la selva, probablemente llamada así porque, según este mito, a partir de ella surgieron los demás vegetales. Un ave comió sus bayas y de sus excrementos nació el kurunjy'ü, uno de los primeros arbolitos pioneros de los bosques secundarios. Del excremento del ave que comió sus frutos surgió un ejemplar de yvyra ñamandu (el árbol del creador), una especie también heliófila pero más durable y de gran altura, cuyas semillas aladas no palatables, dispersadas por el viento desde sus cápsulas dieron origen a todas las especies vegetales. Lo interesante de esta narrativa es que amalgama en una sola secuencia de acontecimientos la ontogenia y la filogenia de todo un ecosistema. También hay que destacar que en esta sucesión es justamente una de las especies arbóreas por excelencia portadoras de la conciencia subjetiva del creador, la que da lugar a la diversidad biológica.

Por su parte, narrativas de los guaraníes de la parcialidad Ava Chiripa sugieren que antes de abandonar su residencia terrenal, el primer ancestro transformó a su hija mayor en una colosal planta de yerba mate, denominada $k a$ 'a guachu (yerba mate gigante/selva inmensa). Las numerosas y heterogéneas ramas de este árbol colosal produciríanlas semillas de las más diversas especies nativas, garantizando así la regeneración y reproducción a perpetuidad de la selva ${ }^{5}$, inclusive después de su extinción total debido a cataclismos apocalípticos como el mencionado gran incendio o la tala indiscriminada de

\footnotetext{
${ }^{5}$ Ndee remopotĩmba retermina ko yvyra teĩ, el mimo koropi pecha e’i árami ko ñande ru kuery ko yvy oundi ramo, ñande oundipa aguã rami ojapo ramo a'ekuery, el mimo ko kampo va'ekue-ekue el mimo opytapaju ka'aguypa juta a'eramingua a'egui py: "Podéis hacer una tala raza completa, y acabar hasta con el último árbol, del mismo modo como cuando nuestros dioses acaben con esta tierra, cuando hagan de lo suyo para acabar con nosotros, todo quedará como si fuera un campo, y aunque (la tierra) quede así (de diezmada) la selva se alzará nuevamente”.
} 
vigencia corriente. Estas narrativas sobre $k a^{\prime} a$ guachu explican y legitiman la ambivalencia de la expresión $k a$ 'a, actualmente empleada tanto para significar "yerba mate", como así también "selva" o "bosque" (Keller, 2013). Puesto que la cosmología parental de los guaraníes no está basada en la heredabilidad de genes, sino en el traspaso de energía, entendida esta como "conciencia cultural", es interesante la identificación como "nuestra abuela" de la planta madre de toda la selva, ya que los vegetales constituyen un eslabón generacional intermediario dentro del linaje energético iniciado por el progenitor solar, y dilatado por los niños recién nacidos. En razón de ello, estos últimos son consagrados al creador en la ceremonia del bautismo que se lleva a cabo en primavera (ñemongarai), utilizándose ramas de yerba mate como uno de los elementos vinculantes entre las deidades y los niños. Durante esta ceremonia, las ramas de yerba mate se cuelgan en el templo junto con otros elementos y son empleadas a modo de oráculo para averiguar el patronímico sagrado de los niños. Posteriormente deben ser ingeridas en infusión por sus progenitores y familiares.

\section{Origen edáfico y selvático posdiluviano}

Para los guaraníes Paĩ Tavytera del Paraguay, la especie que cumple la función de deidad creadora de los árboles es el arary (Cadogan, 1968: 89). Si bien el autor no da más precisiones sobre el motivo de esta consideración cosmológica, es probable que ella guarde relación con la restauración posdiluvial de la tierra, ya que el arary suele conformar isletas de bosques casi puros en paleocauces del río Paraná en Argentina y Paraguay (Fig. 1A). Unas pocas otras especies arbóreas se emplazan en los bordes de estas isletas de bosque, transmitiendo la imagen de una biodiversidad leñosa incipiente que es irradiada desde un núcleo arbolado muy denso y monoespecífico de arary. Estos bosques flotantes aislados en los pastizales que cubren los paleocauces, sugieren también la noción de un rudimentario sustrato posdiluvial surgido desde la base de un árbol.

Por su parte, los mbya sugieren que la tierra posdiluvial fue creada por el sujeto supremo como una obra de alfarería, depositando espirales de sustrato edáfico en torno a una palmera pindo mítica. Cuentan las narrativas orales que mediante esta palmera algunos representantes de su grupo étnico pudieron evadir el advenimiento de las aguas y alcanzar la morada solar del primer ancestro. Tratándose de una especie que si bien crece en ambientes palustres no es muy tolerante a la inundación, es posible que su participación en este mito se deba a la gran altura que exhiben algunos ejemplares (Fig. 1B).

No se han recogido relatos entre los $A v a$ Chiripa acerca del origen posdiluvial de la tierra o de la selva. Sin embargo es sugestivo el comportamiento ecológico de la especie a la cual denominan $k a$ 'a mirĩ, es decir, "selva primigenia". Se trata de un congénere palustre de la yerba mate con hojas más pequeñas y también dables de ser ingeridas en infusión. Estudios fitosociológicos recientes sugieren que esta especie, que cohabita junto al arary, es la que con mayor frecuencia aparece aislada en los esteros que cubren algunos sectores de dichos paleocauces (Fig. 1C) y que además se comporta como especie nodriza conformando bajo su copa un sitio con cobertura graminosa más laxa, donde se establece la regeneración de diferentes especies leñosas (Fig. 1D) a partir de diásporas excretadas por aves que se asientan en ella. En el sitio se observa toda una gradación de fragmentos de bosque desde ejemplares aislados de ka'a mirĩ (selva incipiente), pasando por bosquetes pequeños flanqueados por ejemplares de dicha especie (Fig. 1E) hasta los grandes fragmentos con amplia predominancia de arary (Keller \& al., inéd.). La expresión "mirĩ' se traduce como "pequeña", "incipiente" o "primigenia", de manera que, considerando el rol pionero de la especie en la conformación de fragmentos de bosques en sitios otrora inundados, la traducción de “ $k a$ 'a mirĩ" sería legítimamente ambivalente, por un lado podría significar "yerba pequeña", pero también es posible su interpretación como "selva incipiente". A partir de la observación de esta dinámica fitosociológica palustre se pudo haber destilado la noción del origen de una selva biodiversa a partir de las semillas de una sola especie de Ilex L. (Aquifoliaceae). Subsecuentemente dicha noción habría sido extendida desde 

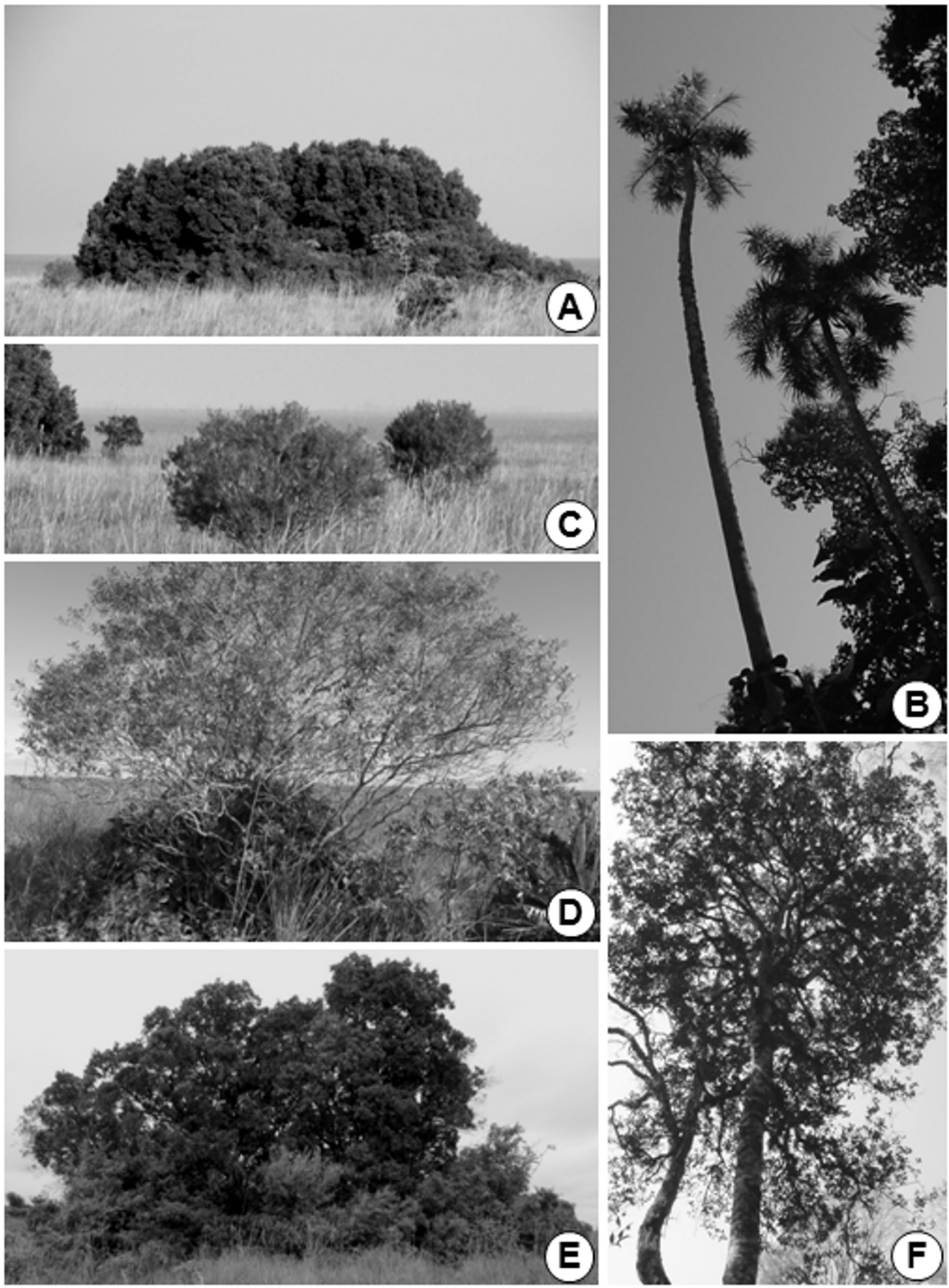

Fig. 1. A: Bosque de arary en paleocauce anegado del río Paraná, su interior es prácticamente monoespecífico, apareciendo algunas otras especies arbóreas en sus bordes. B: Ejemplar de palmera pindo de más de $25 \mathrm{~m}$. C: Ejemplares aislados de $k a^{\prime} a$ mirĩ en paleocauce del río. D: Ejemplar de $k a$ 'a mirĩ albergando regeneración natural de leñosas en su base. E: Bosquete de arary en paleocauce. F: Ejemplar de yerba mate o ka'a guachu de más de $20 \mathrm{~m}$. 
los pequeños bosquetes higrófilos a las áreas extensas cubiertas de selva, dando lugar a la antinomia entre dos principios generativos de biodiversidad: ka'a mirĩ y ka'a guachu, siendo la primera especie, limitada en tamaño, la encargada de posibilitar la conformación de "selvas pequeñas" y la segunda, un árbol que alcanza mayor tamaño (Fig. 1F) la encargada de la génesis de "selvas extensas".

\section{Yvyra}

El término yvyra es usado en lengua guaraní para significar árbol, palo, madera, garrote, bastón, (Guasch \& Ortiz, 1995; Montoya, 1639). Una aproximación etimológica sugerida por Cadogan (1957), traduce la expresión como "fruto de la tierra" (yvy: tierra, $a$ : fruto). Se trata de una etimología que hace alusión al atributo de germinación compartido con todas las plantas terrestres. Sin embargo, si consideramos el rol geogónico de los árboles durante la creación del mundo (estructura de varas ígneas cruzadas) y la restauración de la tierra posdiluviana (centro de formación o surgimiento edáfico), podemos sugerir el significado de la expresión yvyra (yvy: tierra; $r \tilde{a}$ : sufijo de futuro o factibilidad) como "aquello a partir de lo cual emerge la tierra".

\section{Conclusiones}

Los resultados expuestos permiten concluir que la interpretación de los mitos constituye una avenida fructífera para el análisis de expresiones fitonímicas guaraníes y que el escrutinio mitográfico debe sustentarse tanto en la etnografía y cosmología, como así también en atributos morfológicos y dinámicos de las especies, poblaciones y elementos tratados en las narrativas míticas.

\section{Agradecimientos}

A los guaraníes que compartieron conmigo sus narrativas y conocimientos. Al Dr. Gustavo Giberti por la identificación de ejemplares de ka'a mirĩ. Al Ing. Antonio Krapovickas por su asesoramiento bibliográfico. A los revisores por sus oportunas sugerencias.

\section{Bibliografía}

ALBUQUERQUE U. P. \& J. A. HURRELL. 2010. Ethnobotany: one concept and many interpretations. In U. P. Albuquerque \& N. Hanazaki (eds.). Recent developments and case studies in Ethnobotany. SBEE/NUPEEA, Recife, pp. 87-99.

ASSIS, V. DE. \& I. J. GARLET. 2004. Análise sobre as populações guarani contemporâneas: demografia, espacialidade e questões fundiárias. Revista de Indias 64(230): 35-54.

AZEVEDO, M.; A. BRAND; A. M. GOROSITO; E. HECK; B. MELIÁ \& J. SERVÍN. 2009. Guaraní Retã 2008, los pueblos guaraníes en las fronteras, Argentina, Brasil y Paraguay. B. Meliá (ed.), AGR servicios gráficos, Asunción, 23 pp.

BERLIN, B. 1973. Folk Systematics in Relation to Biological Classification and Nomenclature. Annual Review in Ecological Systems Vol. 4: 259-271.

BÖHREN, A. V. 2005. Evaluación del potencial para la producción de chapas decorativas de 13 especies arbóreas de la selva misionera. Informe de tesis para la Maestría en Ciencias de la Madera, Celulosa y Papel. Universidad Nacional de Misiones, Posadas, $181 \mathrm{pp}$.

- H. M. GARTLAND, L. A. GRANCE \& H. A. KELLER. 2005. Ficha técnica: Árboles de Misiones, Holocalyx balansae Micheli. Yvyrareta 13: 83-86.

CADOGAN, L. 1957. Breve contribución al estudio de la nomenclatura guaraní en Botánica. Ministerio de Agricultura y Ganadería. Servicio Técnico Interamericano de Cooperación Agrícola. Boletín nro. 194, Asunción, 49 pp.

—. 1959. Ayvu rapyta. Vol. 227. Antrop. 5. Universidad de São Paulo, Brasil, 321 pp.

- 1968. Chono Kybwyra: aporte al conocimiento de la mitología guaraní.

1992. Diccionario Mbya-Guaraní-Castellano. Biblioteca Paraguaya de Antropología, Asunción, 17: 1-211.

DIMITRI, M. J. 1973. El libro del árbol. Ed. Celulosa Argentina, Buenos Aires, $52 \mathrm{pp}$.

GONZÁLEZ, L. 2009. Etnotaxonomía nahua ligada a las deidades del panteón mesoamericano. Las plantas de Quetzalcóatl-Ehécatl entre los Nahuas del norte de Guerrero. SIPIG-UNAM. Guerrero, 10 pp.

GUASCH, A. \& D. ORTIZ. 1995. Diccionario Castellano-Guaraní, Guarani-Castellano. Sintáctico, fraseológico, ideológico. $12^{\circ}$ edición. C. E. P. A. G. Asunción, $826 \mathrm{pp}$.

KELLER, H. A. 2003. Mythical origin of Chusquea ramosissima Lindm. (Poaceae), the ancient knife of the Guaranis. Economic Botany 57 (4): 461-471.

2008. Etnobotánica de comunidades guaraníes de Misiones, Argentina. Valoración de la vegetación como fuente de recursos. Tesis de doctorado en 
Recursos Naturales, Facultad de Ciencias Agrarias, Universidad Nacional del Nordeste, $282 \mathrm{pp}$.

2009. Plantas textiles de los guaraníes de Misiones (Argentina). Bonplandia 18 (1): 29-37.

. 2010. Importancia de las especies con "madera de ley" para los guaraníes de Misiones, Argentina, Revista Forestal Yvyraretá 17: 28-34.

—. 2011. Problemas de la etnotaxonomía guaraní: "las plantas de los animales". Bonplandia 20 (2): 111136.

. 2013. Ka'aguachu: "la selva en un sólo árbol". Una contribución de la mitología ava chiripa a la toponimia de la región guaranítica. Estudios Socioterritoriales: Revista de Geografía 13 (ene-jun): 101-123.

LANGE, J. 1966. Primitive Plantenavne, og deres gruppering efter motiver. Ed. J. Jøgensen \& Co Bogtrykkeri. København.

LATZINA, E. 1937. Index de la flora dendrológica argentina. Lilloa 1: 95-212.

LITAIFF, A. 1999. Les Fils du Soleil: mythe et pratique des Indiens Mbya-Guarani du littoral du Brésil. 1999. Tese (Doutorado em Antropologia) - Universidade de Montreal/ Canadá.

MARTÍNEZ, G. J. 2009. Fitonimia de los Tobas Bermejeños (Chaco Central, Argentina). En J. Braunstein \& C. Messineo (comp.), Hacia una nueva carta étnica del Gran Chaco 8, pp. 194-212. Centro del Hombre Antiguo Chaqueño, Buenos Aires.

MONTOYA, R. DE (S.J.). 1639. Tesoro de la lengua guaraní. Imprenta Juan Sánchez, Madrid, 814 pp.

MÜLLER, F. 1989 [1935]. Etnografía de los Guaraní del Alto Paraná. Ed. Socieatis Verbi Divini, Rosario, $132 \mathrm{pp}$.
NIMUENDAJU (UNKEL), C. 1978 [1914]. Los mitos de creación y de destrucción del mundo como fundamento de la religión de los Apapokuva-Guaraní. G. Juergen Riester (Ed.), Centro amazónico de Antropología y Aplicación Práctica. Serie Antropológica I. Lima, 219 pp.

NOELLI, F. S. 2004. Settlement patterns and environmental changes in human occupation on the left bank of the Paraná river (Paraná State, Brazil). Revista sobre Arqueología en Internet 6 (1): 1-24

POUJADE, R.A. 1995. Mapa arqueológico de la provincia de Misiones (Cartilla explicativa). Artes gráficas Zamphirópolos S.A. Asunción, pp. 7-8.

REAL ACADEMIA ESPAÑOLA. 1973. Diccionario enciclopédico ilustrado. Ed. Oriente S. A. Buenos Aires, 3 tomos, $1041 \mathrm{pp}$.

SCARPA, G. F. 2007. Hacia una etnotaxonomía vegetal Chorote I: Fitonimia, sistema nomenclatural y comparación dialectal. Suplemento Antropológico 42 (1): 81-119.

SCHMITZ, P.I. 1991. Migrantes da Amâzonia: A Tradição Tupiguaraní. En A. Kern \& al.: Arqueologia préhistórica do Rio Grande do Sul. P. 295-330. Porto Alegre.

SUÁREZ, M. E. 2010. Fitonimia wichí de especies arbóreas y arbustivas del Chaco Semiárido salteño. En C. Messineo, G.F. Scarpa \& F. Tola (comp.), Léxico y categorización etnobiológica en grupos indígenas del Gran Chaco, pp. 199-224. Inst. Lingüística, Fac. Cs. Humanas, Universidad Nacional de La Pampa, Santa Rosa.

2011. Fitonimia wichí de hierbas y bejucos del Chaco semiárido salteño, Argentina. Bonplandia 20 (2): 185-202.

Original recibido el 1 de octubre de 2013; aceptado el 7 de noviembre de 2013. 
Apéndice: Glosario de fitónimos guaraníes utilizados en el texto.

Aju'y: "madera luminosa", nombre de diversas lauráceas, especialmente Nectandra megapotamica (Spreng.) Mez (Lauraceae), de amplio uso tradicional en la confección de encendedores de varilla giratoria o "tipo taladro".

Aju'y mirĩ: "pequeño laurel”. En virtud de su uso como pieza de los encendedores tradicionales, es probable que también se trate de Nectandra megapotamica (Spreng.) Mez (Lauraceae).

Arary: Calophyllum brasiliensis Cambess. (Calophyllaceae).

$\boldsymbol{K} \boldsymbol{a}$ 'a: selva / nombre genérico de la yerba mate y de algunos congéneres.

Ka'a guachu: "selva de gran tamaño" / nombre específico de Ilex paraguariensis A. St.-Hil. (Aquifoliaceae).

Ka’a mirĩ: "selva pequeña", "selva incipiente" / nombre de Ilex dumosa Reissek var. guaranina Loes. (Aquifoliaceae).

Ka'e ete'i: "la auténtica planta", nombre de Solanum americanum Mill. (Solanaceae).

Kurunjy'ũ: Trema micrantha (L.) Blume (Celtidaceae).

Pindo: palmera / denominación guaraní de Syagrus romanzoffiana (Cham.) Glassman (Arecaceae). Su etimología alude a las hojas agrupadas en lo alto del estípite.

Tajy: "por donde baja el fuego o rayo", nombre del lapacho, Handroanthus heptaphyllus (Vell.) Mattos (Bignoniaceae).

Yvi: textil / fitónimo aplicado a Ceiba speciosa (A. St.-Hil., A. Juss. \& Cambess.) Ravenna (Bombacaceae).

Yvyra: árbol, especie leñosa, leño. En esta contribución sugerimos su etimología como "aquello a partir de lo cual emerge la tierra".

Yvyra ñamandu: el árbol del creador, nombre que recibe el cedro misionero, Cedrela fissilis Vell. (Meliaceae).

Yvyrapepe: "árbol con aletas", denominación de Holocalyx balansae Micheli (Fabaceae).

Yvyratái: duramen de Holocalyx balansae Micheli (Fabaceae). Su etimología probablemente hace referencia a su empleo para encender fuego, o a su peso y dureza. Su peso específico varía de 0,9 a $1 \mathrm{~kg} /$ $\mathrm{dm}^{3}$ (Böhren \& al., 2005; Dimitri, 1973). Su dureza en dirección normal a las fibras es de 3,73 Unidades Brinell (Latzina, 1937), o bien de 1022-1042 kg/cm² (Böhren, 2005). 